\title{
VIOLÊNCIAS CONTRA ESTUDANTES NO CAMPUS DE UMA UNIVERSIDADE FEDERAL BRASILEIRA
}

Sales Augusto dos Santos ${ }^{1}$

Resumo: Este artigo é fruto de uma pesquisa quantitativa que realizamos com quatrocentos estudantes de graduação da Universidade Federal de Viçosa (UFV). A pesquisa foi financiada pela Pró-Reitoria de Educação da universidade. Nosso objetivo neste artigo é interrogar, por meio de argumentos e evidências empíricas, a afirmação de uma renomada pesquisadora de que "o estupro é de fácil diagnóstico". As evidências utilizadas para demonstrar que a constatação desse tipo de violência sexual pode não ser tão fácil foram obtidas dos dados empíricos de uma pesquisa supracitada, cujo objetivo era investigar as violências praticadas contra os/as discentes de graduação da universidade, especialmente as do sexo feminino. Os argumentos utilizados para inquirir a afirmação supracitada foram obtidos da literatura sobre o tema. Conclui-se que não se pode afirmar sem ponderações que o estupro é de fácil diagnóstico no meio univeristário.

Palavras chave: Violência na universidade. Estudantes. Mulheres. Violência Sexual. Diagnóstico.

Abstract: This article is the result of quantitative research that we conducted with four hundred undergraduate students of the Universidade Federal de Viçosa (UFV). The research was funded by the Dean of Education of the aforementioned university. Our aim in this paper is to interrogate, through arguments and empirical evidence, the statement of a renowned researcher that "rape is easily diagnosed." The evidence used to demonstrate that the diagnostic of this type of sexual violence may not be so easy was obtained from the empirical data of the research mentioned above, which aimed to investigate the violence practiced against undergraduate

\footnotetext{
${ }^{1}$ Doutor em Sociologia pela Universidade de Brasília (UnB), com Pós-Doutorado pela Brown University. É Professor Voluntário do Departamento de Ciências Sociais (DCS) da Universidade Federal de Viçosa (UFV) e Senior Research Specialist at the Department of African \& African Diaspora Studies of the University of Wisconsin Milwaukee (UWM), ano letivo de 2019/2020.
} 
students, especially female students. The arguments used to inquire the above statement were obtained from the literature about the subject. It can be concluded that it cannot be stated without consideration that rape is easily diagnosed in the university environment. Keywords: University violence. Students. Women. Sexual violence. Diagnosis.

\section{Introdução}

Conforme a professora e pesquisadora Mercedes Prieto da Facultad Latinoamericana de Ciencias Sociales (FLACSO)-Ecuador, nas universidades de todos os países da América Latina tem havido denúncias de assédio sexual, entre outras violências de gênero, praticadas contra as estudantes mulheres. Segundo Prieto, "El 2018 fue un año marcado, en América Latina, por mujeres en las calles, en tomas de planteles educativos y en el ciberespacio denunciando violencias de género $\mathrm{y}$

2 Consultado a 30.05.2018, em http://www.unwomen.org/es/news/stories/2017/ 11/feature-bangladesh-students-say-no-moresexual-harassment.

3 Consultado a 30.05.2018, em https://www.amnistia.org/ve/blog/2018/02/4864 /el-acoso-sexual-en-las-universidades.

4 Vide a matéria "As ameaças que escandalizaram universidade britânica: acoso sexual en escenarios académicos"

(Prieto, 2019: 15).

Ao que tudo indica, o sofrimento de assédio sexual pelas estudantes de sexo feminino nas universidades, entre entras violências, é um problema mundial, visto que nos últimos anos algumas instituições de renome internacional, como a Onu Mujeres $^{2}$ e a Anistia Internacional, ${ }^{3}$ assim como os meios de comunicação de massa, tais como jornais, televisão e Websites, têm noticiado práticas de violências sexuais contra as estudantes nos campi das universidades de alguns países europeus, como na Inglaterra, ${ }^{4}$ sul-americanos, como na Argentina, ${ }^{5}$

\footnotetext{
'Estuprem as meninas para dar uma lição'". Consultado a 28.05.2019, em https://www.bbc.com/portuguese/internacional48438652.

5 Consultado a 05.04.2019, em https://www.clarin.com/sociedad/uba-abriosumario-escrache-profesor-acusado-acososexual_0_OGfEaMmo1.html.
} 
Bolívia, ${ }^{6}$ Colômbia, ${ }^{7}$ Chile, ${ }^{8}$ Equador, ${ }^{9}$ norte-americanos, como no México ${ }^{10}$ e nos Estados Unidos da América, ${ }^{11}$ africanos, como na África do Sul, ${ }^{12} \mathrm{e}$ países asiáticos, como Bangladesh. ${ }^{13}$

\section{Na América do Sul o Brasil não}

foge à regra quanto às violências praticadas contra as estudantes universitárias do sexo feminino. Nas universidades brasileiras há casos de violências física, sexual, psicológica, racial, de orientação sexual, entre outras, contra as estudantes mulheres, que ocorrem simultaneamente ou não dentro de salas de aulas, laboratórios, bibliotecas, alojamentos estudantis, entre outros espaços universitários. Por exemplo, segundo reportagem publicada no programa televisivo Fantástico, da Rede Globo de Televisão, edição do dia

\footnotetext{
6 Consultado a 15.06.2018, em https://www.eldeber.com.bo/septimodia/Elacoso-sexual-en-las-universidades-se-sabe-perose-calla-20171019-0085.html.

7 Consultado a 05.09.2017, em https://www.vice.com/es_co/article/paak38/sile ncio-vice-acoso-sexual-universidades-colombiaexiste-investigacion-connectas.

8 Consultado a 25.04.2019, em https://www.latercera.com/nacional/noticia/acos o-sexual-investigan-132-casos-16universidades/252893/.

9 Consultado a 25.04.2019, em https://www.elcomercio.com/actualidad/docente s-destituidos-acoso-universidad-central.html.

10 Consultado a 05.05.2019, em https://www.mexico.com/nuestrascausas/acoso-sexual-universidades-mexicodenuncias-2018/.
}

28/09/2014, no Brasil, “casos de estupro têm se multiplicado em universidades do país. ${ }^{14,}$

Contudo, ao que parece, o tema violências contra as estudantes universitárias nos campi universitários brasileiros ainda é um assunto tabu. Praticamente não há pesquisas acadêmico-científicas sobre o tema no Brasil, visto que não há um campo de pesquisa consolidado sobre esse tema, mesmo havendo violências concretas (d)enunciadas pelas vítimas de Norte ao Sul do País, a exemplo das que já ocorreram na Universidade Federal do Acre (UFAC), ${ }^{15}$ Universidade Federal da

11 Consultado a 05.09.2017, em https://www.bbc.com/portuguese/noticias/2014/ 05/140506_estupros_universidades_eua_pai. 12 Consultado a 05.05 .2019 , em https://www.timeslive.co.za/news/southafrica/2018-10-10-university-of-limpopolecturer-suspended-over-sexual-harassmentallegations/.

13 Consultado a 30.05.2018, em http://www.unwomen.org/es/news/stories/2017/ 11/feature-bangladesh-students-say-no-moresexual-harassment.

14 Consultado a 05.06.2017, em http://g1.globo.com/fantastico/noticia/2014/09/a lunas-lutam-contra-violencia-sexual-commulheres-em-universidades.html.

15 Consultado a 26.02.2016, em http://ujs.org.br/index.php/noticias/ujsfeministacontra-a-violencia-sexual-nas-universidadesbrasileiras/. 
Bahia (UFBA), ${ }^{16}$ Universidade de Brasília (UnB), ${ }^{17}$ Universidade Federal de Minas Gerais (UFMG), ${ }^{18}$ Universidade São Paulo $(U S P)^{19}$ e Universidade Federal do Paraná (UFPR). ${ }^{20}$ Nessas universidades, entre outras, foram registrados casos de assédio sexual, assédio moral, estupro, tentativa de estupro, desqualificação intelectual, entre outras violências praticadas por professores e estudantes homens contra as estudantes mulheres.

\section{Os campi da Universidade} Federal de Viçosa (UFV), não estão livres das violências denunciadas pelas estudantes das Instituições de Ensino Superior (IES) públicas supracitadas, visto que estudantes da UFV já haviam denunciado ocorrências de casos de “estupro, abuso, assédio e discriminação,

\footnotetext{
16 Consultado a 28.02.2016, em https://www.correio24horas.com.br/noticia/nid/ professor-da-ufba-e-afastado-apos-serdenunciado-por-alunas/

17 Consultado a 28.02.2016, em http://ujs.org.br/index.php/noticias/ujsfeministacontra-a-violencia-sexual-nas-universidadesbrasileiras/.

18 Consultado a 28.02.2016, em http://g1.globo.com/fantastico/noticia/2014/09/a lunas-lutam-contra-violencia-sexual-commulheres-em-universidades.html.

19 Consultado a 28.02.2016, em http://g1.globo.com/fantastico/noticia/2014/09/a lunas-lutam-contra-violencia-sexual-commulheres-em-universidades.html e <http://revistaforum.com.br/digital/173/universi dade-e-violencia-contra-mulheres-vamos-falarserio-sobre-o-assunto/.
}

que são frequentes no dia a dia da instituição" (Narde, 2015).

A pesquisa que Santos (2018) realizou com discentes de graduação da UFV, entre os meses de junho e julho de 2016, ratificou as denúncias supracitadas. Na época em que foi realizada a pesquisa, a UFV tinha 11.239 estudantes de graduação, dos quais 400 foram entrevistados/as no campus Viçosa, ${ }^{21}$ por meio de questionário, sendo $51 \%$ dos entrevistados do sexo masculino e $49 \%$ do sexo feminino. Os resultados da pesquisa indicaram que os/as estudantes soforem 31 tipos de violências na universidade e/ou em festas acadêmicas, conforme se verá ao longo deste texto.

Como não temos espaço neste artigo para descrever e analisar todas as

\footnotetext{
20 Consultado a 28.02.2016, em http://g1.globo.com/fantastico/noticia/2014/09/a lunas-lutam-contra-violencia-sexual-commulheres-em-universidades.html.

21 A UFV possui três campi: (a) o campus Viçosa, o principal, que "oferece cursos de graduação e programas de pós-graduação estricto sensu, em níveis de mestrado (acadêmico e profissional) e doutorado, além de cursos de pósgraduação lato sensu (presenciais e a distância)"; (b) o campus Florestal, que "oferece cursos técnicos concomitantes ao ensino médio, cursos técnicos ministrados após o término do ensino médio, bem como cursos de graduação e programas de pós-graduação em nível de mestrado"; e (c) o campus Rio Paranaíba, que "oferece cursos de graduação e programas de pós-graduação em nível de mestrado (acadêmico e profissional)". Consultado a 05.06.2017, em https://www.ufv.br/a-ufv/campi/.
} 
violências (d)enunciadas pelos/as estudantes de graduação da UFV, focaremos em um tipo de violência, o estupro. Nosso objetivo aqui é buscar estabelecer um diálogo com a professora Diva Muniz e, especialmente, interrogar, por meio de argumentos e evidências empíricas, a sua afirmação de que "o estupro é de fácil diagnóstico" (Muniz, 2017: 37).

\section{A escassez de produção acadêmico- científica no Brasil sobre violência contra estudantes nos campi universitários}

Embora seja considerável a bibliografia sobre o tema violência no Brasil (Porto, 2015), inclusive sobre violência contra as mulheres (Bandeira, 2014), a literatura sobre Violência contra estudantes nos campi universitários brasileiros ainda é muito incipiente. Ao que tudo indica, poucos são os/as autores/as que têm se dedicado a escrever sobre o tema, como, por exemplo, Almeida (2017), Bandeira e Almeida (2011), Porto (2017) e Schwantes e Andrade (2017). Praticamente não há produção de conhecimento sobre o tema, que parece ser um tabu no Brasil. Portando, mais raras ainda são pesquisas quantitativas e qualitativas sobre o assunto. Mais ainda, essas, quando existem, foram realizadas muito recentemente, ou seja, após a segunda metade da década de 2010.

Assim, não é sem razão que encontramos apenas três pesquisas relativas ou correlatas ao tema violências nos campi universitários brasileiros. A primeira que encontramos foi feita por Oliveira e Santibanez (2015), cujo título é "Violência, conflitos e crimes nos campi universitários: subsídios para a política de segurança da UFG. Relatório de Pesquisa”. Essa pesquisa não focou diretamente na violência contra os/as estudantes, visto que tinha um escopo mais abrangente: a política de segurança no campus da Universidade Federal de Goiás (UFG). Seus autores fizeram uso de duas abordagens basicamente. A primeira, quantitativa, que tinha como objetivo:

identificar e analisar as ocorrências relativas a conflitos intersubjetivos, crimes e contravenções nos câmpus da UFG, incluídas as regionais (situadas em Catalão, Jataí e Cidade de Goiás) que tenham sido registradas tanto no âmbito interno da Universidade, quanto em delegacias de polícia competentes para averiguar crimes e contravenções na região em que os câmpus se situam. (Oliveira e Santibanez, 2015: 5) 
A segunda abordagem, qualitativa, que tinha como objetivo:

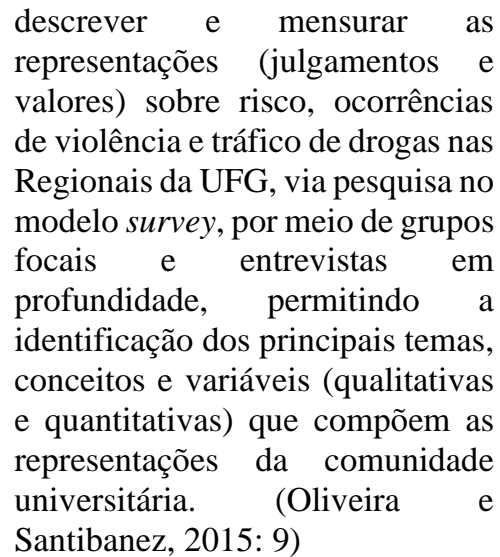

A segunda pesquisa que encontramos sobre o tema Violência contra estudantes nos campi universitários brasileiros foi realizada pelo Instituto Avon (2015), cujo título é "Violência contra a mulher no ambiente universitário". Segundo o próprio Instituto Avon,

A pesquisa foi realizada ao longo de setembro e outubro de 2015 , com universitários dos cursos de graduação e pós-graduação. Ela contou com uma fase quantitativa, realizada online, e uma qualitativa, com grupos de discussão envolvendo universitários de ambos os sexos e entrevistas em profundidade com especialistas. Em ambas as fases foram coletados depoimentos dos estudantes (Instituto Avon, 2015). ${ }^{22}$

Foram entrevistados/as 1.823 estudantes de instituições de ensino

22 Consultado a 10.07.2017, em https://agenciapatriciagalvao.org.br/violencia/pe superior públicas $(24 \%)$ e privadas (76\%) de todo o Brasil, sendo $60 \%$ de entrevistadas do sexo feminino e $40 \%$ do sexo masculino. Mais da metade dos/as entrevistados/as, 51\%, tinham entre 16 e 25 anos, $35 \%$ de 26 a 35 anos, $10 \%$ de 36 a 45 anos e $4 \%$ acima de 45 anos. A maioria dos/as estudantes entrevistados/as, 53\%, era de classe média, $36 \%$ eram de classe alta e $12 \%$ eram de classe baixa.

Focada na "violência contra a mulher no ambiente universitário", essa pesquisa constatou várias agressões contra as discentes no ambiente acadêmico e/ou em festas acadêmicas, visto que $67 \%$ das estudantes mulheres afirmaram ter sofrido algum tipo de violência nesses espaços. Por exemplo, $56 \%$ das estudantes afirmaram ter sofrido assédio sexual e $11 \%$ sofreram tentativa de abuso enquanto estavam sob efeito de álcool (Instituto Avon, 2015).

Diferentemente da pesquisa de Santos (2018), que será descrita mais à frente, na pesquisa do Instituto Avon os questionários foram respondidos online, enquanto na pesquisa daquele/a pesquisador/a os questionários foram entregues diretamente ao/à squisa-violencia-contra-a-mulher-no-ambienteuniversitario/. 
entrevistado/a por um/a entrevistador/a e aquele/a o respondia imediatamente na presença desse/a, mas sem a sua interferência. Outra diferença importante é que a pesquisa de Santos (2018) foi feita somente com estudantes de graduação de uma universidade federal, portanto, pública. A pesquisa do Instituto Avon (2015) foi mais abrangente, uma vez que entrevistou estudantes de graduação e pós-graduação de universidades públicas e privadas.

A terceira pesquisa que encontramos sobre o tema foi realizada por Martins et al. (2017), e cujo título é "Violência sexual na Universidade Federal de Viçosa: 'Boa noite Cinderela Acadêmico"'. Semelhante à pesquisa de Santos (2018), visto que também teve como campo de pesquisa a UFV, assim como o tema violência contra as estudantes mulheres no campus Viçosa dessa universidade, a pesquisa de Martins et al. (2017) tem relação direta com o nosso artigo. Contudo, o trabalho desses/as autores/as limitou-se a investigar, por meio de documentos obtidos em redes sociais e por questionários online (aplicados via Internet), um tipo específico de violência: a sexual ou os "crimes sexuais" contra as estudantes de sexo feminino. Como os/as autores/as afirmam:

Esse trabalho é um desafio
colocado frente à curiosidade
investigativa do tema violência
sexual, pois se reporta à prática dos
crimes sexuais no interior da
universidade: prática relativizada
na instituição acadêmica, a partir
do comportamento assumido por
alguns estudantes, que exige
reconhecer em seus alunos como
agressores na rotina das relações
interpessoais [...]. Esse trabalho
objetivou uma maior compreensão
das práticas de violência sexual
envolvendo estudantes
universitários. Sua hipótese inicial
alude à fragilidade de
reconhecimento das vítimas e
agressores desse tipo de crime,
pela dificuldade clássica aplicada à
obtenção de dados consistentes e
minimamente qualificados sobre o
fenômeno. (Martins et al., 2017: $3-$
5)

Por um lado, se a primeira pesquisa, sobre a política de segurança na e da UFG, de Oliveira e Santibanez (2015), era bem mais ampla que a de Santos (2018), a pesquisa de Martins et al. (2017) era menos abrangente. Ou seja, essa última era mais restrita que a pesquisa de Santos (2018), pois tinha como foco somente "os crimes sexuais" contra as estudantes mulheres no interior da UFV e em festas acadêmicas. Por outro lado, como foi visto anteriormente, a pesquisa do Instituto Avon (2015) também se diferencia da pesquisa de Santos (2018), visto que utilizou 
metodologia de pesquisa diferente, bem como teve público e campo de pesquisa diferentes.

Devemos destacar que, embora as pesquisas do Instituto Avon (2015) e de Santos (2018) tenham revelados vários tipos de violências iguais e/ou semelhantes praticadas contra as estudantes do sexo feminino, não podermos compará-las em razão dos argumentos expostos no parágrafo acima. Em realidade, não podemos fazer comparações com e/ou entre nenhuma das quatro pesquisas supracitadas, visto que elas têm metodologias, objetivos e públicos pesquisados distintos. Assim, neste artigo focaremos na descrição de algumas violências que foram enunciadas pelos/as estudantes da UFV na pesquisa de Santos (2018), bem como analisaremos uma delas, o estupro. Como afirmamos anteriormente, visamos questionar se esse crime é de fácil diagnóstico, como afirmou a pesquisadora Diva Muniz (2017).

\section{Violências contra os/as estudantes da UFV}

Como citado anteriormente, a pesquisa de Santos (2018) foi realizada com 400 estudantes de ambos os sexos da UFV, campus Viçosa. Do total de estudantes entrevistados/as, 21,25\% afirmaram que tinham sofrido pelo menos um tipo de violência na universidade ou em festas acadêmicas, $72,25 \%$ afirmaram que não sofreram violências nesses espaços, 5,25\% disseram que não sabiam se haviam sofrido algum tipo de agressão e 1,25 não respondeu à questão (Santos, 2018: 134). Após perguntar quem havia sofrido algum tipo de violência na universidade, Santos (2018) perguntou aos/às estudantes que responderam afirmativamente a essa questão de qual ou quais violências eles/as tinham sido vítimas. Os/as respondentes da questão enunciaram trinta e um tipos de violências, como se pode verificar no Quadro 1, que foi construída em ordem decrescente de respostas (Santos, 2018: 140). Dessa forma, Santos também construiu um ranking das violências (d)enunciadas pelos/as estudantes, uma vez que o Quadro 1 começa com a violência mais manifestada pelos/as estudantes, "levar cantada ofensiva" [que é uma violência praticada tipicamente pelos homens contra as mulheres na sociedade brasileira], e termina com a menos manifestada, "ser ameaçada/o de morte" [uma violência 
que pode ser praticada e sofrida por ambos os sexos dos estudantes, embora quem a manifestou na UFV tenha sido exclusivamente estudantes homens] (Santos, 2018: 171).

Observa-se que as violências contidas no Quadro 1 foram automanifestadas tanto por estudantes do sexo masculino quanto do sexo feminino. Porém, Santos (2018) interseccionou os tipos de violências sofridas com o sexo dos/as estudantes. Assim, constatou que foram as estudantes mulheres quem mais enunciaram que foram vítimas de violências na universidade ou em festas acadêmicas, visto que, do total dos/as estudantes entrevistados/as que afirmaram ter sofrido algum tipo de violência, 58,80\% eram mulheres e 41,20\% eram homens (Santos, 2018: 165).

A partir dessa constatação, Santos (2018) buscou verificar quais violências eram as mais praticadas contra as estudantes mulheres e contra os estudantes homens. Por meio de alguns critérios, quem não vamos descrever ou analisar neste artigo, Santos criou o que denominou de tipologia das violências praticadas contra os/as estudantes da UFV. Esta tipologia teve como objetivo categorizar os trinta e um tipos de violências enunciados pelos/as estudantes (Quadro 1). Isto é, Santos visou demonstrar, didaticamente, que alguns tipos de violências estavam propensos a acontecer, e aconteceram, mais ou totalmente contra as estudantes mulheres da UFV, enquanto outros tipos estavam propensos a acontecer, e aconteceram, mais ou totalmente contra os estudantes homens, assim como alguns tipos de violências foram iguais ou semelhantes em relação a ambos os sexos.

Quadro 1 - Tipos de violências automanifestadas pelos/as estudantes

\begin{tabular}{|l|c|c|c|}
\hline \multicolumn{1}{|c|}{ Tipo de violência } & $\begin{array}{c}\text { Frequência } \\
\text { absoluta das } \\
\text { respostas }\end{array}$ & $\begin{array}{c}\text { Frequência } \\
\text { relativa (\%) a } \\
363 \text { respostas }\end{array}$ & $\begin{array}{c}\text { \% em relação } \\
\text { ao total de } \\
\text { entrevistados/a } \\
\text { s }\end{array}$ \\
\hline $1^{\text {a) }}$ Levar cantada ofensiva & 32 & 8,81 & 8,00 \\
\hline $2^{\text {a }}$ Ouvir piadas LGBTfóbicas & 29 & 7,98 & 7,25 \\
\hline $3^{\text {a }}$ Ouvir piadas machistas/sexistas & 28 & 7,71 & 7,00 \\
\hline $\begin{array}{l}4^{\text {a }} \text { ) Agressão psicológica [desqualificação pessoal, ser } \\
\text { diminuída/o ou rebaixada/o enquanto ser humano, } \\
\text { tentativa de destruição da autoestima, etc.] }\end{array}$ & 26 & & \\
\hline
\end{tabular}


Periódico do Núcleo de Estudos e Pesquisas sobre Gênero e Direito Centro de Ciências Jurídicas - Universidade Federal da Paraíba

V. 8 - $\mathrm{N}^{\mathrm{o}} 05$ - Ano 2019

ISSN | 2179-7137 | http://periodicos.ufpb.br/ojs2/index.php/ged/index

$\left.5^{\mathrm{a}}\right)$ Trote

$6^{\mathrm{a}}$ ) Assédio sexual

$7^{\mathrm{a}}$ ) Desrespeito ao corpo [tocar ou passar a mão em

você sem seu consentimento]

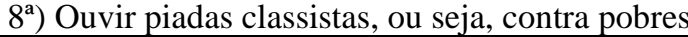

$9^{\text {a) }}$ Ouvir piadas racistas

$9^{\text {a) }}$ Ser intimidada/o

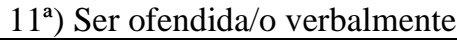

$\left.12^{a}\right)$ Ser coagida a dar ou receber beijo de alguém

$13^{\mathrm{a}}$ ) Ser desqualificada/o intelectualmente

$\left.14^{\mathrm{a}}\right)$ Assédio moral

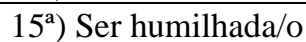

$15^{\mathrm{a}}$ ) Furto [quando se é furtado o ladrão não tem

contato com a vítima]

$17^{a}$ ) Agressão física [ser empurrada/o, levou tapa, um

chute, foi espancada/o, etc.]

$\left.17^{a}\right)$ Ser ameaçada/o de agressão física

$\left.17^{\mathrm{a}}\right)$ Ser ridicularizada/o

$20^{\mathrm{a}}$ ) Coagida/o a ingerir bebida/s alcoólica/s

$21^{a}$ ) Roubo [quando se é roubado o ladrão tem contato

com a vítima, ameaçando-a ou agredindo-a]

$\left.22^{\mathrm{a}}\right)$ Estupro

$22^{\text {a) }}$ Ser difamada/o

$22^{\mathrm{a}}$ ) Coagida/o a fumar maconha

$25^{\mathrm{a}}$ ) Tentativa de estupro

$25^{\text {a) }}$ Sofrer tortura

$25^{\text {a }}$ ) Colocaram drogas em sua bebida e você a tomou

sem saber

$28^{\text {a }}$ ) Não fui aceito no alojamento estudantil porque sou

gay

$28^{a}$ ) Ter fotos íntimas publicadas na Internet sem sua

autorização

$28^{a}$ ) Ter vídeos íntimos publicados na Internet sem sua autorização

$28^{\text {a) }}$ Ser ameaçada/o de morte

Total

Fonte: Santos (2018).

Desta maneira, Santos (2018)

fez a seguinte classificação, que também podem ser observadas no Figura 1:

(a) violências exclusivas contra as estudantes mulheres: estupro, tentativa de estupro, tortura, ter fotos íntimas publicadas na internet, ter vídeos íntimos publicados na internet e ingerir, sem saber, bebidas com drogas;

\begin{tabular}{l|l}
6,88 & 6,25 \\
\hline 6,61 & 6,00 \\
6,06 & 5,50 \\
\hline 5,50
\end{tabular}

\begin{tabular}{l|l}
6,50 & 5,00
\end{tabular}

$4,40 \quad 4,00$

\begin{tabular}{l|r}
4,40 & 4,00
\end{tabular}

\begin{tabular}{l|r}
4,13 & 3,75 \\
\hline 3,58 & 3,25
\end{tabular}

\begin{tabular}{l|r}
4,13 & 3,75 \\
3,58 & 3,25
\end{tabular}

\begin{tabular}{l|r}
3,58 & 3,00 \\
\hline 3,30 & 2,75
\end{tabular}

\begin{tabular}{l|l}
3,03 & 2,75 \\
\hline
\end{tabular}

\begin{tabular}{l|r}
3,03 & 2,75 \\
\hline 2,75 & 2,50 \\
\hline
\end{tabular}

\begin{tabular}{l|l|l}
10 & 2,75 & 2,50 \\
8 & 2,20 & 2,00 \\
\hline
\end{tabular}

\begin{tabular}{l|l|l}
10 & 2,75 & 2,50 \\
8 & 2,20 & 2,00 \\
\hline
\end{tabular}

\begin{tabular}{l|l|l}
8 & 2,20 & 2,00 \\
\hline 8 & 2,20 & 2,00
\end{tabular}

\begin{tabular}{|c|c|c|}
\hline 6 & 1,65 & 1,50 \\
\hline 5 & 1,38 & 1,25 \\
\hline 3 & 0,82 & 0,75 \\
\hline 3 & 0,82 & 0,75 \\
\hline 3 & 0,82 & 0,75 \\
\hline 2 & 0,55 & 0,50 \\
\hline 2 & 0,55 & 0,50 \\
\hline 2 & 0,55 & 0,50 \\
\hline 1 & 0,27 & 0,25 \\
\hline 1 & 0,27 & 0,25 \\
\hline 1 & 0,27 & 0,25 \\
\hline 1 & 0,27 & 0,25 \\
\hline 363 & 100,00 & $\mathrm{XXX}$ \\
\hline
\end{tabular}


(d) violências majoritariamente

contra os estudantes homens: ser ridicularizado e ser humilhado;

(e) violências com tendência a acontecer contra as estudantes mulheres: roubo, ouvir ofensas verbais, ouvir piadas racistas, ouvir piadas classistas;

(f) violências com tendência a acontecer contra os estudantes homens: trote, ser coagido a bebidas alcoólicas e coagido a fumar maconha; e

(g) violências comuns contra os dois sexos: ser furtado, ser agredido fisicamente, ser agredido psicologicamente, ser intimidado/a, ser desqualificado/a intelectualmente, ouvir piadas LGBTfóbicas, não ser aceito no alojamento estudantil porque é gay e não ser aceito no alojamento estudantil porque é lésbica.

Como se pode observar no Figura 1, salvo a tipificação violências comuns aos dois sexos [até porque elas são comuns aos dois sexos], nas demais tipificações sempre há mais denúncias de sofrimento de tipos de violências por parte das mulheres que pelos homens, ratificando que, do total de estudantes que afirmaram ter sofrido algum tipo de violência, a maioria $(58,80 \%)$ era mulher e a minoria $(41,20 \%)$, homem.

Portanto, não é sem sentido que haja mais tipos de violências na classificação de violências exclusivas contra as estudantes mulheres (6 tipos) do que em violências exclusivas contra os estudantes homens (1 tipo), assim como mais tipos de violências na classificação violências majoritárias contra as estudantes mulheres (6 tipos) que em violências majoritárias contra os estudantes homens (2 tipos) e assim sucessivamente. 


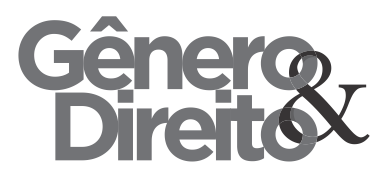

Periódico do Núcleo de Estudos e Pesquisas sobre Gênero e Direito

Centro de Ciências Jurídicas - Universidade Federal da Paraíba

V. 8 - No 05 - Ano 2019

ISSN | 2179-7137 | http://periodicos.ufpb.br/ojs2/index.php/ged/index

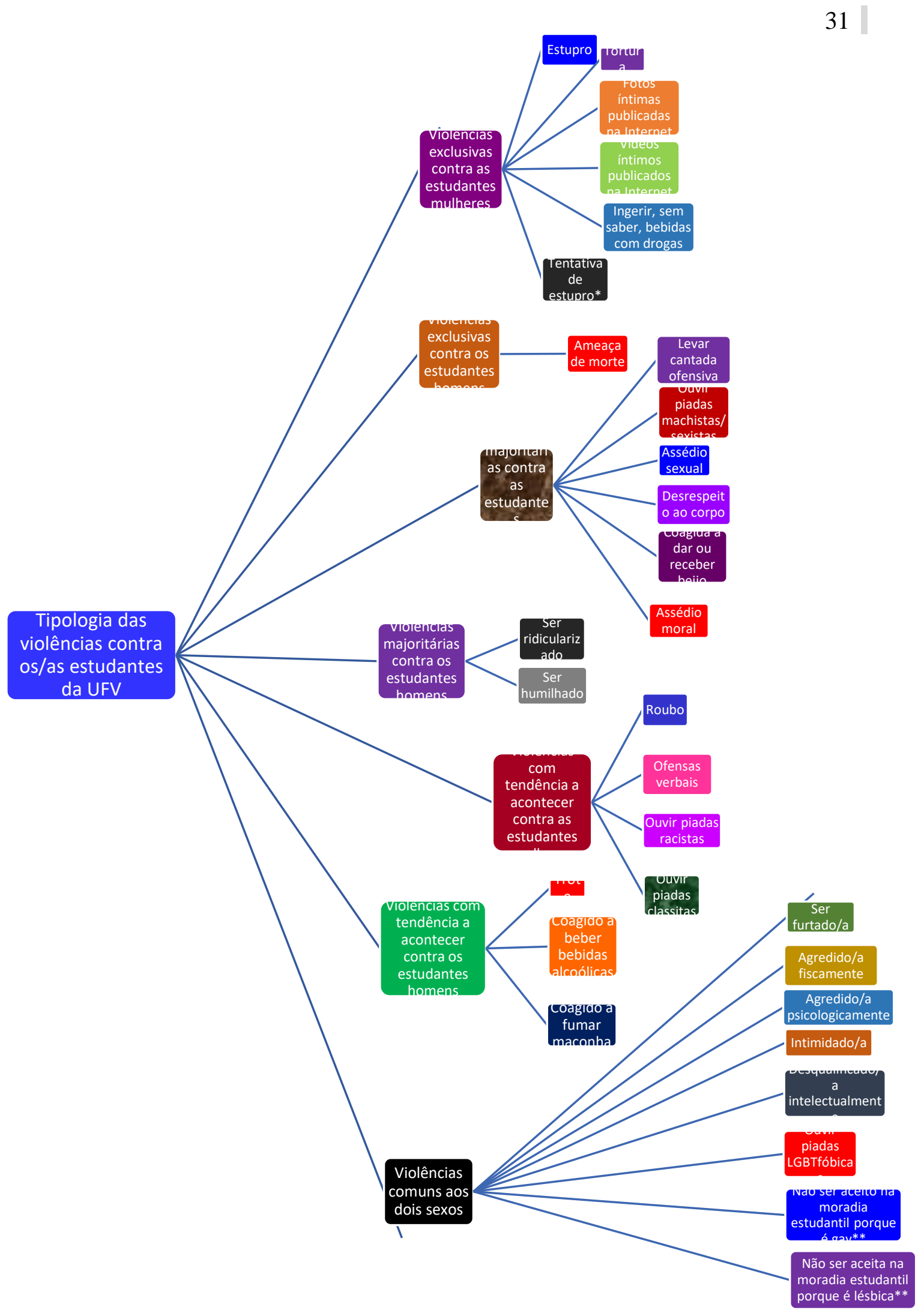

Fonte: Santos (2018)

* Tipificamos a "tentativa de estupro" como uma violência histórico-estrutural e/ou exclusiva contra as mulheres, apesar de os dados da pesquisa indicarem como sendo uma violência comum aos dois sexos. 
** Tipificamos a violência "não foi aceito na moradia estudantil porque é gay" e a "não foi aceita na moradia estudantil porque é lésbica" como violências comuns aos dois sexos, em razão de a discriminação em razão da orientação sexual afetar os dois sexos.

\section{Estupro: crime de fácil diagnóstico?}

Todavia, em alguns casos, devemos ponderar quanto ao fator quantitativo, quer dizer, quanto a considerar a violência que é a mais enunciada como a mais significativa para a pesquisa ou ainda a mais agressiva contra a vítima, assim como ser a mais importante para a descrição e análise do tema pesquisa. Por exemplo, "levar cantada ofensiva" na universidade ou em festas acadêmicas foi a violência mais enunciada pelos/as estudantes entrevistados/as da UFV (Quadro 1), com 32 respostas (Santos, 2018). Já a violência de estupro ficou em vigésimo segundo lugar no ranking da Quadro 1, visto que foram enunciadas apenas três respostas afirmativas com relação a essa última violência. Poderíamos pensar que este último caso, o de estupro, não seria considerado um grande problema para a universidade, visto que houve pouca automanifestação dessa violência.

Pensamos que devemos, primeiro, refletir sobre essas violências e

\footnotetext{
${ }^{23}$ Lei n. 8.072, de 25/07/1990, que "dispõe sobre os crimes hediondos, nos termos do Art. 5, inciso XLIII, da Constituição Federal, e determina
}

perguntamo-nos qual o peso delas para as vítimas? Ou seja, qual das duas violências supracitadas é a mais agressiva e/ou traumática para a vítima? Ao que tudo indica é o estupro. Portanto, não é sem razão que ele é considerado um crime hediondo no Brasil. ${ }^{23}$

Segundo, devemos lembrar que as pesquisas sobre estupro no Brasil indicam que no máximo $10 \%$ dos casos são notificados e/ou denunciados à polícia. Por exemplo, conforme a pesquisa "Estupro no Brasil: uma radiografia segundo os dados da saúde", de autoria dos pesquisadores Daniel Cerqueira e Danilo Santa Cruz Coelho, publicada em 2014 pelo Instituto de Pesquisa Econômica Aplicada (Ipea): “a cada ano no Brasil 0,26\% da população sofre violência sexual, o que indica que haja anualmente 527 mil tentativas ou casos de estupros consumados no país, dos quais $10 \%$ são reportados à polícia" (Cerqueira e Coelho, 2014: 6). Ou seja, a subnotificação de estupro, bem como da tentativa de estupro, é uma característica nacional. Sendo assim, isto é,

outras providências". Disponível em: http://www.planalto.gov.br/ccivil_03/Leis/L807 2.htm. Acesso em: 10 jul. 2017. 
considerando o histórico de baixa notificação nacional desse crime (Cerqueira e Coelho, 2014), parece ser plausível supor que há uma tendência de as estudantes da UFV que foram vítimas de estupro seguirem o padrão nacional com relação à notificação desse crime $\mathrm{e}$ não denunciá-lo. Por isso o seu baixo índice de enunciação pelas estudantes da UFV.

Pensamos que a caraterística de subnotificação do crime de estupro no Brasil, associada a evidências empíricas da pesquisa de Santos (2018), que veremos abaixo, nos permitem questionar a assertiva da professora Diva do Couto Gontijo Muniz, da Universidade Brasília (UnB), de que o estupro é de fácil diagnóstico. Segundo a professora:

Os crimes de estupro, assassinato de mulheres e feminicídio são a expressão mais cruel dessa desigualdade [entre homens e mulheres], uma ferida aberta e exposta em nosso cotidiano social. É uma chaga que sangra e ressangra, que é aberta e reaberta, que não cicatriza, não obstante as múltiplas profilaxias pensadas e utilizadas para removê-la do corpo social, extirpá-la do tecido social e cultural. Embora de fácil diagnóstico é, porém, uma ferida de difícil tratamento e cura porque gerada e gestada em campo propício: o da cultura do

${ }^{24}$ A citação é explícita, ou seja, não se refere somente ao estupro, mas também ao assassinato de mulheres e ao feminicídio. Em função dos patriarcado. (Muniz, 2017: 37, grifos nossos). ${ }^{24}$

Primeiro, devemos lembrar que as relações sociais não são lineares. Ao contrário, são extremamente complexas e/ou dinâmicas para afirmarmos, taxativamente, que o crime de estupro é “de fácil diagnóstico". Tal assertiva, confrontada com o que indicam alguns dados da pesquisa de Santos (2018), ao que tudo indica, é no mínimo questionável, uma vez que esses dados nos permitem apresentar argumentos consistentes em sentido contrário à afirmação de Muniz (2017), como veremos a seguir.

Como já se afirmou em parágrafos anteriores e como pode ser observado no Quadro 1, houve apenas três enunciações de estupro feitas por estudantes do sexo feminino da UFV (Santos, 2018). Contudo, como se verá, quando as estudantes foram perguntadas quem praticou esse crime contra elas, as suas respostas indicaram seis estupradores. Logo, é plausível afirmar que houve mais estupros do que a quantidade de vítimas de estupros. Isto é, apesar de algumas estudantes terem

objetivos deste artigo, faremos comentários somente a respeito do crime de estupro. 
(d)enunciado que foram vítimas de estupro, elas não esclareceram ou explicitaram se (ou que) foram vítimas mais de uma vez desse crime, até porque Santos (2018) não perguntou para as vítimas quantas vezes elas haviam sido estupradas.

Assim, se considerássemos a quantidade de estupros como sendo apenas as três enunciações feitas anteriormente (Quadro 1), ou seja, se as considerássemos como um "diagnóstico fácil", aquele que se apresentou à primeira vista, ${ }^{25}$ poderíamos ter um diagnóstico superficial e enganoso do crime de estupro na UFV, visto que a quantidade de estupradores denunciados foi maior do que a quantidade de vítimas.

Foi possível chegar a essa conclusão porque Santos (2018) interseccionou a violência estupro com o sexo da vítima e o tipo de agressor. Seu objetivo aqui, ao que tudo indica, era saber quem praticou estupro e contra quem. Por exemplo, no Quadro 2 observa-se que houve três enunciações da violência de estupro feitas por estudantes do sexo feminino. Essa é a informação comum aos quadros de número 2 a 5 . Uma das diferenças entre esses quadros é que cada uma mostra uma categoria de estuprador. Por exemplo, o Quadro 2 mostra que uma das estudantes vítimas de estupro afirmou que um dos seus estupradores foi um professor. Portanto, uma pessoa teoricamente conhecida da vítima, que merece um comentário à parte.

Quadro 2 - Estupro, segundo o tipo de agressor e o sexo do/da estudante

\begin{tabular}{|c|c|c|c|c|c|c|}
\hline \multirow{2}{*}{ Estupro } & \multirow{2}{*}{$\begin{array}{c}\text { Sexo da } \\
\text { vítima }\end{array}$} & \multirow{2}{*}{ Números exibidos } & \multicolumn{3}{|c|}{ Agressor: professor } & \multirow[t]{2}{*}{ Total } \\
\hline & & & Sim & Não & Não respondeu & \\
\hline \multirow{10}{*}{ Sim } & \multirow{5}{*}{ Feminino } & Frequência absoluta & 1 & 2 & 0 & 3 \\
\hline & & $\%$ linha & 33,3 & 66,7 & & 100,0 \\
\hline & & $\%$ coluna & 100,0 & 100,0 & & 100,0 \\
\hline & & $\%$ total de estud. estupradas & 33,3 & 66,7 & & 100,0 \\
\hline & & $\%$ total de entrevistados/as & 0,25 & 0,5 & & 0,75 \\
\hline & \multirow{5}{*}{ Total } & Frequência absoluta & 1 & 2 & 0 & 3 \\
\hline & & $\%$ linha & 33,3 & 66,7 & & 100,0 \\
\hline & & $\%$ coluna & 100,0 & 100,0 & & 100,0 \\
\hline & & $\%$ total de estud. estupradas & 33,3 & 66,7 & & 100,0 \\
\hline & & $\%$ total de entrevistados/as & 0,25 & 0,5 & 0 & 0,75 \\
\hline
\end{tabular}

Fonte: Santos, 2018.

${ }^{25}$ Que foram algumas das respostas à pergunta "Que tipo de violência você foi vítima no campus da UFV ou em festas acadêmicas?", feita aos/às entrevistados/as. 
Por um lado, se o estupro praticado por um desconhecido é traumático, causando vários problemas físicos, psicológicos, sexuais, entre outros, à vítima desse crime, por outro, imagina-se o estupro praticado por um colega de sala de aula ou, como no caso acima, um professor? Não temos respostas para nomear, qualificar ou indicar os prováveis danos físicos $\mathrm{e}$ mentais/psíquicos na vítima. Basta lembrarmos que deve ser mais que tortura $^{26}$ ter de encarar o violentador do seu corpo, do seu sexo e/ou da sua mente pelo menos duas vezes por semana. ${ }^{27}$ Dito de outra maneira, sofre-se outra/s violência/s $\mathrm{s}^{28} \mathrm{e}$, no mínimo, mais um crime hediondo: a tortura. ${ }^{29} \mathrm{O}$ que estamos supondo aqui é que, quando o estuprador é um conhecido da estudante, ela sofre sobremaneira, porque é punida novamente quando paga o ônus do

\footnotetext{
${ }^{26}$ Este foi outro tipo de violência que também foi enunciado pelos/as estudantes da UFV (Santos, 2018).

${ }^{27}$ Em geral, na UFV as disciplinas de quatro créditos são ofertadas duas vezes na semana com carga horária de no mínimo 100 minutos por encontro.

${ }^{28}$ Aliás, Santos (2018: 149-150) sugere que um ato de violência não expressa somente a violência declarada pela vítima, mas contém vários outros tipos de violência, o que o autor denomina de "coquetel de violências". Por exemplo, o desrespeito ao corpo da estudante é precedido e/ou praticado simultaneamente com vários
}

estupro. Isto é, para não serem torturadas com a presença de seu estuprador e/ou do praticante de outras agressões sofridas, muitas estudantes desistem de ir às aulas quando o seu algoz faz ou ministra uma disciplina que ela está cursando. Conforme Almeida:

É necessário e premente encontrar soluções a curto prazo e jurídicas para momentos em que uma estudante esteja em situação de vulnerabilidade diante do seu agressor/ofensor, não deixando que ela siga com o ônus da violência perpetrada e que esta ainda não está configurada como crime. Ou seja, estudantes que trancam disciplinas ou o curso porque seu(s) agressor(es) seguem frequentando a universidade sem qualquer restrição, constrangendoas com sua simples presença ou com intimidações sutis ou explícitas. (Almeida, 2017: 394)

Assim, pensamos ser plausível levantar a hipótese, por mais perversa que possa ser, de talvez o estupro praticado por um conhecido possa ser mais prejudicial ou mais nocivo que o

outros tipos de violência, como, por exemplo, assédio sexual, violência psíquica, tortura, entre outras.

${ }^{29} \mathrm{Em}$ realidade a tortura é um crime equiparado ao crime hediondo, conforme o Inciso XLIII, do Art. 5 da Constituição da República Federativa do Brasil, de 1988. Consultado a 10.07.2017, em http://www.planalto.gov.br/ccivil_03/constituica o/constituicaocompilado.htm; e Art. 2 da Lei n. 8.072, de 25/07/1990. Consultado a 10.07.2017, em

http://www.planalto.gov.br/ccivil_03/Leis/L807 2.htm. 
praticado por um desconhecido. E dizemos que tal hipótese é perversa porque acreditamos que só quem sabe do peso da sua dor, do seu sofrimento, é quem a está carregando, pois, como medir o pior estupro? O fato é que ele não deveria existir. Contudo, existindo um estupro de um professor contra uma aluna essa violência não deve ser silenciada pelos pares do agressor, pois, como nos lembra Almeida (2017), a "lei do silêncio", nesse caso da conivência, protege os agressores.

Retornando desse rápido comentário sobre o estupro, aqui devemos enfatizar que, quando afirmamos acima que "um dos seus estupradores" foi um professor, estamos apresentando, por um lado, a hipótese de que uma estudante vítima de estupro pode ter sofrido esta violência sexual mais de uma vez não somente pelo mesmo criminoso, como também por diferentes agressores, como se verá abaixo. Por outro lado, enfatizamos que essa hipótese não surgiu de um vácuo de evidências empíricas. Ao contrário, foi a partir dos dados da pesquisa de Santos (2018) que apresentamos essa resposta provisória, ou seja, essa hipótese (Giddens, 2002).
Santos (2018) interseccionou a violência de "estupro" com o sexo das vítimas, assim como com quem foi o praticante da violência. Os dados resultantes desses cruzamentos indicam que as estudantes que sofreram essa violência foram estupradas mais de uma vez, visto que a quantidade de perpetradores de estupro, (d) enunciada pelas vítimas, é maior que a quantidade da ocorrência de "estupros" declarada por elas, como citado anteriormente. Por exemplo, no Quadro 3, três estudantes mulheres de graduação da UFV afirmam que foram estupradas por três estudantes de graduação da Universidade que elas não conheciam, ou seja, sem proximidade com a vítima. $\mathrm{Se}$ iniciássemos a descrição do estupro, segundo o tipo de agressor e o sexo da vítima, por esse quadro e não observássemos mais nenhum cruzamento de dados com as outras categorias de agressores, uma vez que já tínhamos a informação anterior de que foram (d)enunciados três estupros, tenderíamos a concluir, equivocadamente, que as três ocorrências de estupro foram praticadas somente pelos três estudantes sem proximidade com a vítima, uma vez que 
aparentemente tínhamos três ocorrências

de estupro e três estupradores.

Quadro 3 - Estupro, segundo o tipo de agressor e o sexo do/da estudante

\begin{tabular}{|c|c|c|c|c|c|c|}
\hline \multirow[t]{2}{*}{ Estupro } & \multirow[t]{2}{*}{ Sexo } & \multirow{2}{*}{ Números exibidos } & \multicolumn{3}{|c|}{$\begin{array}{l}\text { Agressor: estudante de graduação } \\
\text { sem proximidade com a vítima }\end{array}$} & \multirow[t]{2}{*}{ Total } \\
\hline & & & Sim & Não & Não respondeu & \\
\hline \multirow{10}{*}{ Sim } & \multirow{5}{*}{ Feminino } & Frequência absoluta & 3 & 0 & 0 & 3 \\
\hline & & $\%$ linha & 100,0 & & & 100,0 \\
\hline & & $\%$ coluna & 100,0 & & & 100,0 \\
\hline & & $\%$ total de estud. estupradas & 100,0 & & & 100,0 \\
\hline & & $\%$ total de entrevistados/as & 0,75 & & & 0,75 \\
\hline & \multirow{5}{*}{ Total } & Frequência Absoluta & 3 & 0 & 0 & 3 \\
\hline & & $\%$ linha & 100,0 & & & 100,0 \\
\hline & & $\%$ coluna & 100,0 & & & 100,0 \\
\hline & & $\%$ total de estud. estupradas & 100,0 & & & 100,0 \\
\hline & & $\%$ total de entrevistados/as & 0,75 & & & 0,75 \\
\hline
\end{tabular}

Fonte: Santos, 2018.

Contudo, Santos (2018) fez o cruzamento de todos os tipos de violência, inclusive a de "estupro", com todas as categorias de agressores/as, assim como com o sexo das vítimas, e o resultado foi revelador na medida em que isso possibilitou enxergar além dos “diagnósticos fáceis" e/ou dos ou resultados "óbvios" ou imaginados, como o fato de uma/s estudante/s ter/em sido estuprada/s mais de uma vez, conforme hipótese citada acima.

Por meio dos resultados dos cruzamentos supracitados observamos, com relação à violência "estupro", que, além de haver denúncias das estudantes de graduação da UFV contra um professor (Quadro 2), havia também a indicação de praticantes desse crime em várias subcategorias de estudantes de graduação, como os três estudantes sem proximidade com a vítima (Quadro 3). Mas houve outras identificações de outros tipos de estudantes de graduação. Por exemplo, no Quadro 4, uma entrevistada afirmou que fora estuprada por um estudante que estudava na mesma sala de aula que ela. No Quadro 5, outra ou a mesma estudante afirmou que foi estuprada por um estudante de graduação que era seu amigo. Ou seja, houve denúncias da prática da violência de estupro não somente contra um professor, mas também contra estudantes de graduação desconhecidos da vítima, os três primeiros do Quadro 3, assim como contra estudantes de graduação conhecidos ou íntimos das estudantes 
Periódico do Núcleo de Estudos e Pesquisas sobre Gênero e Direito Centro de Ciências Jurídicas - Universidade Federal da Paraíba

V. 8 - No 05 - Ano 2019

ISSN | 2179-7137 | http://periodicos.ufpb.br/ojs2/index.php/ged/index

vítimas, os dois dos Quadros 4 e 5,

respectivamente.

Quadro 4 - Estupro, segundo o tipo de agressor e o sexo do/da estudante

\begin{tabular}{|c|c|c|c|c|c|c|}
\hline \multirow[t]{2}{*}{ Estupro } & \multirow[t]{2}{*}{ Sexo } & \multirow[t]{2}{*}{ Números exibidos } & \multicolumn{3}{|c|}{$\begin{array}{l}\text { Agressor: estudante de graduação que } \\
\text { estudava na mesma sala de aula da } \\
\text { vítima }\end{array}$} & \multirow[t]{2}{*}{ Total } \\
\hline & & & Sim & Não & Não respondeu & \\
\hline \multirow{10}{*}{ Sim } & \multirow{5}{*}{ Feminino } & Frequência absoluta & 1 & 2 & $x^{2}$ & 3 \\
\hline & & $\%$ linha & 33,3 & 66,7 & & 100,0 \\
\hline & & $\%$ coluna & 100,0 & 100,0 & & 100,0 \\
\hline & & $\%$ total estud. estupradas & 33,3 & 66,7 & & 100,0 \\
\hline & & $\%$ total de entrevistados/as & 0,25 & 0,5 & & 0,75 \\
\hline & \multirow{5}{*}{ Total } & Frequência absoluta & 1 & 2 & 0 & 3 \\
\hline & & $\%$ linha & 33,3 & 66,7 & & 100,0 \\
\hline & & $\%$ coluna & 100,0 & 100,0 & & 100,0 \\
\hline & & \% total estud. estupradas & 33,3 & 66,7 & & 100,0 \\
\hline & & $\%$ total de entrevistados/as & 0,25 & 0,5 & & 0,75 \\
\hline
\end{tabular}

Fonte: Santos, 2018.

Quadro 5 - Estupro, segundo o tipo de agressor e o sexo do/da estudante

\begin{tabular}{|c|c|c|c|c|c|c|}
\hline \multirow[t]{2}{*}{ Estupro } & \multirow[t]{2}{*}{ Sexo } & \multirow[t]{2}{*}{ Números exibidos } & \multicolumn{3}{|c|}{$\begin{array}{c}\text { Agressor: estudante de graduação } \\
\text { que era amigo da vítima }\end{array}$} & \multirow[t]{2}{*}{ Total } \\
\hline & & & Sim & Não & Não respondeu & \\
\hline \multirow{10}{*}{ Sim } & \multirow{5}{*}{ Feminino } & Frequência absoluta & 1 & 2 & & 3 \\
\hline & & $\%$ linha & 33,3 & 66,7 & & 100,0 \\
\hline & & $\%$ coluna & 100,0 & 100,0 & & 100,0 \\
\hline & & $\%$ total estud. estupradas & 33,3 & 66,7 & & 100,0 \\
\hline & & $\%$ total de entrevistados/as & 0,25 & 0,5 & & 0,75 \\
\hline & \multirow{5}{*}{ Total } & Frequência absoluta & 1 & 2 & & 3 \\
\hline & & $\%$ linha & 33,3 & 66,7 & & 100,0 \\
\hline & & $\%$ coluna & 100,0 & 100,0 & & 100,0 \\
\hline & & $\%$ total estud. estupradas & 33,3 & 66,7 & & 100,0 \\
\hline & & $\%$ total de entrevistados/as & 0,25 & 0,5 & & 0,75 \\
\hline
\end{tabular}

Fonte: Santos, 2018.

Somando-se a quantidade de agressores ou, caso se queira, estupradores, obtêm-se seis perpetradores de "estupro": um professor, três estudantes de graduação sem proximidade com a vítima, um aluno de graduação que estudava na mesma sala de aula que a vítima e um aluno de graduação que era amigo da vítima. Não obstante, entre os tipos de violências (d)enunciadas pelos/as estudantes apareceram três casos de estupro, como se observa no Quadro 1. Ou seja, houve três ocorrências de estupros (d)enunciadas para seis perpetradores ou seis tipos de estupradores, o que nos impeliu a apresentar a hipótese, plausível, de que 
alguma/s estudante/s vítima/s de estupro sofreram esta violência sexual mais de uma vez pelo mesmo estuprador ou por diferentes estupradores.

Assim, considerando os dados supracitados e os argumentos dos parágrafos anteriores, pensamos que não podemos afirmar taxativamente que "o estupro é de fácil diagnóstico", como o fez a pesquisadora Muniz (2017: 37). O nosso questionamento parece ser mais plausível ainda quando consideramos a ponderação da professora Leila Harris sobre a importância do lugar ou local onde aconteceu a violência sexual para o diagnóstico e/ou denúncia da violência. Para esta pesquisadora algumas violências são mais difíceis de serem detectadas em razão do local. Conforme a professora Leila Harris:

A violação do estupro quando vem a público causa comoção na mídia e na sociedade em geral, ainda que por um curto período de tempo, mas a violência na esfera doméstica [incluindo ou não o estupro] é mais difícil de ser detectada justamente por ocorrer no lugar normalmente associado ao afeto e à segurança: o lar. No entanto, mulheres, crianças e, muito mais raramente, homens são vítimas desse tipo de violência. Se no caso do estupro a vergonha e o medo são os principais motivos que levam as vítimas ao silêncio, no caso de violência na família, o medo em geral é acompanhado por um sentimento de lealdade ao agressor. (Harris, 2017: 271).
A reflexão da professora Leila Harris na citação acima demonstra, entre outras possibilidades de leitura e análises, a importância do lugar onde ocorreu o crime para o seu conhecimento mais apropriado ou o mais próximo da realidade possível. E, ao que tudo indica, o lugar onde ocorre o crime de estupro condiciona não somente o diagnóstico da violência, como também a decisão da vítima sobre publicizar [e/ou denunciar legal e amplamente] o crime e o criminoso ou sobre silenciar sobre eles.

Logo, se estamos analisando violências sexuais, especificamente o estupro contra as mulheres na Universidade, imediatamente temos que indagar qual é o imaginário social sobre este ambiente, assim como qual é o próprio imaginário que os/as acadêmicos/as têm sobre a universidade. De maneira geral, a universidade é uma instituição imaginada ou pensada como um lugar também insuspeito para a prática de crimes sexuais graves, especialmente os que causam aversão na sociedade, como o estupro. Ela, a universidade, está associada à racionalidade, ao conhecimento científico, à mais elevada e refinada educação formal. E, lamentavelmente, 
imagina-se que pessoas educadas formalmente no e com ensino superior não cometem crimes sexuais contra estudantes universitários/as. Por conseguinte, se infere que esse espaço de reunião coletiva de intelectuais, de produtores/as e reprodutores/as do conhecimento racional e de pessoas educadas formalmente, é associado, equivocadamente, ao locus dos/das justos/as, "acima do bem e do mal".

Desse modo, e fazendo uma analogia com a afirmação da professora Leila Harris, levantamos a hipótese de que na universidade ou, caso se queira, no mundo acadêmico, a violência de estupro é mais difícil de ser detectada. Até mesmo porque os locais onde se produz conhecimento, onde se aprende e se ensina a produzi-lo com ou por meio de metodologias sofisticadas, são também os locais onde se aprende a esconder ou a distorcer da maneira mais eficiente possível [ou com argumentos com cariz de cientificidade] a verdade ou o conhecimento sobre os fenômenos sociais, econômicos, políticos, culturais, educacionais, entre outros, incluindo aí as violências sexuais, como o estupro. Por conseguinte, mais uma vez é possível questionar se o estupro é "de fácil diagnóstico", uma vez que este não
40

depende só do fato em si, ou seja, do crime para ser conhecido.

\section{Conclusão}

Diante das evidências empíricas da pesquisa de Santos (2018), dos argumentos que construímos neste artigo, associados às reflexões da professora Leila Harris, pensamos ser plausível questionar a afirmação da professora Diva Muniz de que "o estupro é de fácil diagnóstico". A maneira como a autora "lê" a realidade social no que se refere às violências sexuais contra as mulheres, ou seja, de considerar o crime de estupro "de fácil diagnóstico" é, como os dados apresentados neste artigo indicam, limitante para compreendermos essas violências com as complexidades que lhes são peculiares. Fato que pode prejudicar um diagnóstico correto do problema ou, caso se queira, o mais próximo possível da realidade sobre o estupro. Procedendo assim, isto é, tratando o estupro como fenômeno de simples de constatação, provavelmente não conheceremos o real-concreto das violências no meio acadêmico, especialmente os crimes hediondos praticados contra as estudantes mulheres. 
Os dados apresentados neste

artigo também ratificam o que a literatura e/ou as pesquisas sobre estupro no Brasil indicam, a sua provável subnotificação. No caso específico, a sua subnotificação na UFV. Ao que tudo indica, muito provavelmente as estudantes dessa universidade que foram vítimas dessa violência sexual, especialmente as que a sofreram mais de uma vez, não a denunciaram e, consequentemente, contribuíram para o aumento do índice de subnotificação desse crime na universidade, logo no país.

Todavia, deve-se frisar que as estudantes que sofreram este crime na universidade e/ou em festas acadêmicas não o tornaram público por vários motivos, entre os quais alguns que a professora Leila Harris enunciou, além dos fatores indicados na literatura sobre o assunto, como, por exemplo, a exploração ou espetacularização midiática do crime, a tendência à culpabilização da vítima e, consequentemente, a desconfiança com relação ao seu caráter, a humilhação, o sentimento de impunidade, o sofrimento psíquico [que pode levá-la à depressão entre outras doenças], enfim, a vergonha e o medo.

\section{Referências bibliográficas}

Almeida, Tânia Mara Campos (2017), "Violências contra mulheres nos espaços universitários", in Cristina Stevens et al. (orgs.), Brasil. Mulheres e violências: interseccionalidades. Brasília: Technopolitik, 384-399.

Bandeira, Lourdes (2014), "Violência de gênero: a construção de um campo teórico e de investigação", Revista Sociedade e Estado, 29(2), 449-469.

Bandeira, Lourdes; Almeida, Tânia Mara C (2011), "O trote universitário: a festa da intolerância e humilhação feminina", UnB Agência, de 18 de Fevereiro. Consultado a 20.12.2016, em http://www.unb.br/noticias/unbagencia/ artigo.php?id=367.

Cerqueira, Daniel; Coelho, Danilo de Santa Cruz (2014), Estupro no Brasil: uma radiografia segundo os dados da Saúde. Brasília: IPEA.

Giddens, Anthony (2002), Modernidade e identidade. Rio Janeiro: Zahar. 
Harris, Leila A. (2017), "Imagens de violência contra a mulher na literatura chicana contemporânea", in Cristina Stevens et al. (orgs.), Brasil. Mulheres e violências: interseccionalidades. Brasília: Technopolitik, 267-282.

Instituto Avon (2015), "Violência contra a mulher no ambiente universitário". Página consultada a 10.07.2017, em https://agenciapatriciagalvao.org.br/viol encia/pesquisa-violencia-contra-amulher-no-ambiente-universitario/.

Martins, Rogéria et al. (2017), "Violência sexual na Universidade Federal de Viçosa: 'Boa noite Cinderela Acadêmico", in SBS. $\mathbf{1 8}^{\circ}$ Congesso Brasileiro de Sociologia. Anais. Brasília: SBS.

Muniz, Diva do Couto Gontijo (2017), "As feridas abertas da violência contra as mulheres no Brasil", in Cristina Stevens et al. (orgs.), Brasil. Mulheres e violências: interseccionalidades. Brasília: Technopolitik, 36-49.

Narde, Shara (2015), "Combater a cultura da violência dentro das universidades brasileiras", Rebelião, de 08 de Julio. Consultado a 26.02.2016, em https://www.facebook.com/pg/brasil.ujr /posts/?ref=page_internal.

Oliveira, Dijaci David; Santibanez, Dione A. de C. de S. (2015), Violência, conflitos e crimes nos Campus Universitários: subsídios para a política de segurança da UFG. Goiânia: Necrivi, (Relatório de Pesquisa).

Porto, Madge (2017), “O enfrentamento da violência no ambiente universitário: uma experiência na UFAC", in Cristina Stevens et al. (orgs.), Brasil. Mulheres e violências: interseccionalidades. Brasília: Technopolitik, 400-411.

Porto, Maria Stela Grossi (2015), “A violência, entre práticas e representações sociais: uma trajetória de pesquisa", Revista Sociedade e Estado. 30(1), 1937.

Prieto, Mercedes (2019), "Violencias de género $y$ acoso sexual en las universidades del Ecuador". Forum Lasa. 50, Spring, 14-17. Consultado a 28.05.2019 em https://forum.lasaweb.org/.

Santos, Sales Augusto dos (2018), Violências contra os/as estudantes no 
campus Viçosa da UFV. Viçosa:

UFV/PCD/DCI, (Relatório de Pesquisa).

Schwantes, Cíntia Carla Moreira;

Andrade, Vanessa Carvalho de (2017),

"Mulheres no campo da pesquisa em

Física e Ciências Exatas na

contemporaneidade", in Cristina Stevens

et al. (orgs.), Brasil. Mulheres e

violências: interseccionalidades.

Brasília: Technopolitik, 445-456 